Wilgan, K., Stauffer, R., Meindl, M., Geiger, A. (2020): Comparison of tropospheric parameters from Meteodrone measurements with GNSS estimates from ground-based stations. Advances in Space Research, 66, 12, 2812-2826.

https://doi.org/10.1016/j.asr.2020.04.019 


\title{
Comparison of tropospheric parameters from Meteodrone measurements with GNSS estimates from ground-based stations
}

\author{
Karina Wilgan ${ }^{\mathrm{a}, \mathrm{b}, \mathrm{c}, *}$, Raphael Stauffer ${ }^{\mathrm{a}}$, Michael Meindl ${ }^{\mathrm{a}}$, Alain Geiger ${ }^{\mathrm{a}}$ \\ ${ }^{a}$ ETH Zürich, Institute of Geodesy and Photogrammetry, Robert-Gnehm-Weg 15, 8093 Zürich, Switzerland \\ ${ }^{b}$ Technische Universität Berlin, Strasse des 17. Juni 135, 10623 Berlin, Germany \\ ${ }^{c}$ GFZ German Research Centre for Geosciences, Telegrafenberg, 14473 Potsdam, Germany
}

\begin{abstract}
This study presents a comparison of tropospheric parameters, namely zenith tropospheric delay and total refractivity calculated using meteorological measurements from a Meteodrone and Global Navigation Satellite Systems (GNSS) stations. A Meteodrone is a unique Unmanned Aerial Vehicle (UAV) originally designed for automatic measurements of meteorological parameters in vertical profiles (up to $3 \mathrm{~km}$ above ground) for the assimilation into numerical weather prediction models. One profile measured with both ascending and descending drone takes approximately 20 minutes, and there are multiple flights possible during one night. The measurements for this campaign have been conducted in March 2019, in Marbach, Switzerland. We have collected pressure, temperature and humidity profiles from nine flights. From the measured meteorological parameters, we have calculated the refractivity and zenith tropospheric delays $(Z T D \mathrm{~s})$. The parameters are compared with models calculated from 32 neighboring permanent GNSS stations interpolated using the in-house developed least-squares collocation software COMEDIE (COllocation of MEteorological Data for Interpretation and Estimation of tropospheric path delays). The comparisons between the meteo-drones and the GNSS-derived models show a good agreement with an average absolute bias of $2.4 \mathrm{~mm}$ with $1.5 \mathrm{~mm}$ standard deviation for $Z T D$ and $2.7 \mathrm{ppm}$ with $1.7 \mathrm{ppm}$ standard deviation for the comparison of the refractivity. The bias is a result of local changes of meteorological conditions captured by the drone, but not by the interpolation model.
\end{abstract}

Keywords: Meteodrones, UAV, GNSS, troposphere, zenith total delay, refractivity

\section{Introduction}

Water vapor is the most variable parameter of the troposphere and the most abundant greenhouse gas (Bevis et al., 1992). It is also the most critical parameter to observe and accounts for the majority of the errors in the troposphere modeling. A traditional technique for observing the water vapor distribution

\footnotetext{
* Corresponding author

Email address: karina.wilgan@gfz-potsdam.de (Karina Wilgan)
} 
are radiosoundings. The radiosonde is a device measuring meteorological parameters, i.e. air pressure, temperature and humidity, carried by a free-flying balloon up to a height of about 30 kilometers above sea level (asl). Every 30 seconds, the measured values are transmitted to the aerological station using a shortwave transmitter. The measurements are carried out usually twice a day. The spatial resolution of the station's distribution is sparse, usually around 250 kilometers or more in Europe (Guerova et al., 2016).

Another way of observing the water vapor distribution is by using the Global Navigation Satellite Systems (GNSS). This method is called GNSS meteorology, originally GPS meteorology (Bevis et al., 1992) and has been gaining more and more interest over the years. Currently, there are four GNSS constellations with global coverage in operation: US American GPS-NAVSTAR, Russian GLONASS, European Galileo and Chinese Beidou. When a GNSS signal passes through the neutral atmosphere, it is delayed by the refraction with its variations caused mainly by the water vapor. The tropospheric delay used to be considered only as a source of error that needed to be removed. Nowadays, these delays are also a source of interest; e.g. GNSS products are assimilated into nowcasting (Smith et al., 2007; Seco et al., 2009; Manning et al., 2012; Benjamin et al., 2016) or numerical weather prediction (NWP) models (Vedel and Huang, 2004; Poli et al., 2007; Shoji et al., 2009; Zus et al., 2011; Bennitt and Jupp, 2012; Lindskog et al., 2017; Rohm et al., 2019). Moreover, long time series of GNSS observations have become an important source of information for climate studies (Vey et al., 2009; Ning et al., 2013; Alshawaf et al., 2017; Parracho et al., 2018; Klos et al., 2018). On the other hand, the meteorological data can support the GNSS processing, for example in initialization of precise point positioning (PPP) processing algorithms, where the high accuracy troposphere model can shorten the convergence time (Hobiger et al., 2008; Hadaś et al., 2013; Wilgan et al., 2017b; Lu et al., 2017; Wang and Liu, 2019).

A crucial aspect of all the above-mentioned applications is the assessment of the GNSS data quality. The GNSS-based models are often tested against reference data, which can be NWP models (Vedel et al., 2001; Bock et al., 2005; Teke et al., 2011; Wilgan et al., 2017a; Kacmarík et al., 2017), radiometers (Bevis et al., 1992; Duan et al., 1996; Li et al., 2014; Wang and Liu, 2019), or blind models (Wielgosz et al., 2012; Möller et al., 2014) such as the Global Pressure and Temperature (GPT) (Boehm et al., 2007) or the UNB3 (Leandro et al., 2006) models. In the vertical profiles of the atmosphere, the radiosonde measurements are still the state-of-the-art method of a validation (Karabatić et al., 2011; Hurter and Maier, 2013; Rohm et al., 2014; Van Malderen et al., 2014; Douša et al., 2016; Wilgan and Geiger, 2019). However, the soundings are not error-free (Soden and Lanzante, 1996; Wang and Zhang, 2008; Löhnert and Maier, 2012). Apart from the limited temporal and spatial resolution, the radiosonde does not ascend perfectly vertically, as it is carried away by the wind. Moreover, the measuring devices usually cannot be reused after flights, thus, their use is also resource-intensive.

We have conducted a proof of concept campaign of determining the refractivity and consequently the delays at different altitudes using a Unmanned Aerial Vehicle (UAV) called Meteodrone from the Swiss 
company Meteomatics. The Meteodrones were designed for automatic measurements of meteorological parameters in vertical profile for the assimilation into NWP models. For this campaign, the measurements are carried out in Marbach, Switzerland, the test launch site of Meteomatics, during one night with multiple ascends and descends of the drone. Daily flights in many regions are still restricted due to air traffic.

The aim of this work is to compare the measurements from the Meteodrone with the tropospheric parameters from GNSS. For this purpose, the surrounding GNSS permanent stations and three temporarily set-up geodetic GNSS receivers were used to estimate the zenith tropospheric delay $(Z T D)$ and the total refractivity. The GNSS estimates are interpolated to the locations of the drone measurements using the inhouse developed software COMEDIE (COllocation of MEteorological Data for Interpretation and Estimation of tropospheric path delays) (Eckert et al., 1992a,b). The ZTDs and total refractivity from both data sources are compared for all the height levels of the Meteodrones flights.

The Meteodrone is a unique device, as it measures the meteorological parameters, wind and position of a drone. There are a few other studies about meteorological parameters from a drone, but they are mostly covering aspects related only to the wind (Van den Kroonenberg et al., 2008; Niedzielski et al., 2017). The drones were initially equipped with a single frequency GPS receiver for measuring the location of the drone. We have additionally installed a dual-frequency u-blox receiver to calculate the GNSS ZTDs from the moving drone. The decorrelation of the height and the troposphere for this data set is, however, a non-trivial task and needs further studies.

This chapter is followed by Section 2, introducing the experiment and the data sources. Section 3 describes the methods of converting the meteorological observations into tropospheric parameters and the method of the GNSS data interpolation. Section 4 presents the comparison between the GNSS and Meteodrone data, Section 5 discusses the reasons of the differences between the techniques and Section 6 summarizes the study.

\section{The experiment}

In this section, we describe the characteristics of the Meteodrone and the set up for the measurement campaign.

\subsection{The Meteodrone}

The Meteodrone from Meteomatics AG (www.meteomatics.com) is equipped with sensors that measure temperature, wind speed, wind direction, dew point temperature, relative humidity and air pressure with a sampling rate of $250 \mathrm{~ms}$. Figure 1 shows the picture of the Meteodrone at the launch site. The drone size is $70 \mathrm{~cm} \times 70 \mathrm{~cm}$ and its weight is about $1.5 \mathrm{~kg}$. The maximum climb rate is $10 \mathrm{~m} / \mathrm{s}$, and the theoretical maximum altitude is $3000 \mathrm{~m}$ above the ground. The uncertainty of the meteorological sensors 


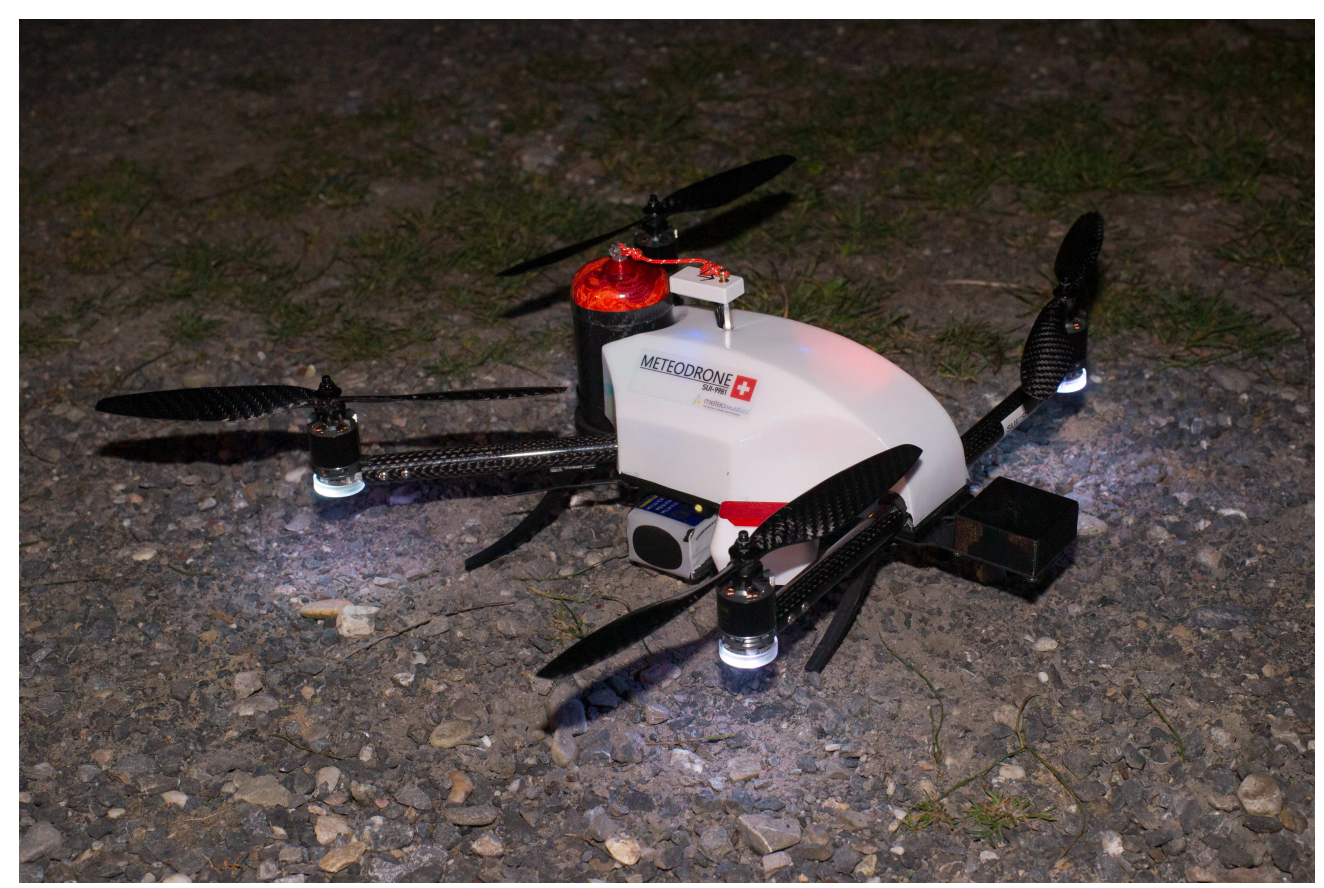

Figure 1: The Meteodrone at the launch site. The red cover protects the emergency parachute.

for temperature, air pressure and relative humidity are given in Table 1. The drone has a Beyond Visual Line-Of-Sight (BVLOS) permit issued by the Federal Office of Civil Aviation (FOCA), which means that it is able to fly within clouds and in a fog. The Meteodrone has a water resistant certificate IP64, thus, it is also capable of flying in the rain. The main limitation is the severe wind: the drone cannot be operated with the wind exceeding $50 \mathrm{~km} / \mathrm{h}$.

Table 1: The uncertainty of the meteorological sensors on board the Meteomatics Meteodrone (Hammerschmidt 2019, private communication)

\begin{tabular}{ll}
\hline parameter & standard deviation \\
\hline temperature & $\pm 0.1 \mathrm{~K}$ \\
air pressure & $\pm 1.5 \mathrm{hPa}$ \\
relative humidity & $\pm 1.8 \%$ (between $0-90 \%)$ \\
\hline
\end{tabular}

\subsection{The experimental set-up}

The flights were carried out in the night of March 28 - 29, 2019 at the test launch site of Meteomatics; close to the municipality of Marbach, canton St. Gallen, Switzerland. The site is located at around $413 \mathrm{~m}$ asl. Prior to the launch, two geodetic Leica GR10 GNSS receivers were installed a few kilometers away from the launch site at different altitudes, one in Chornberg at about $740 \mathrm{~m}$ asl and one in the St. Anton Pass 


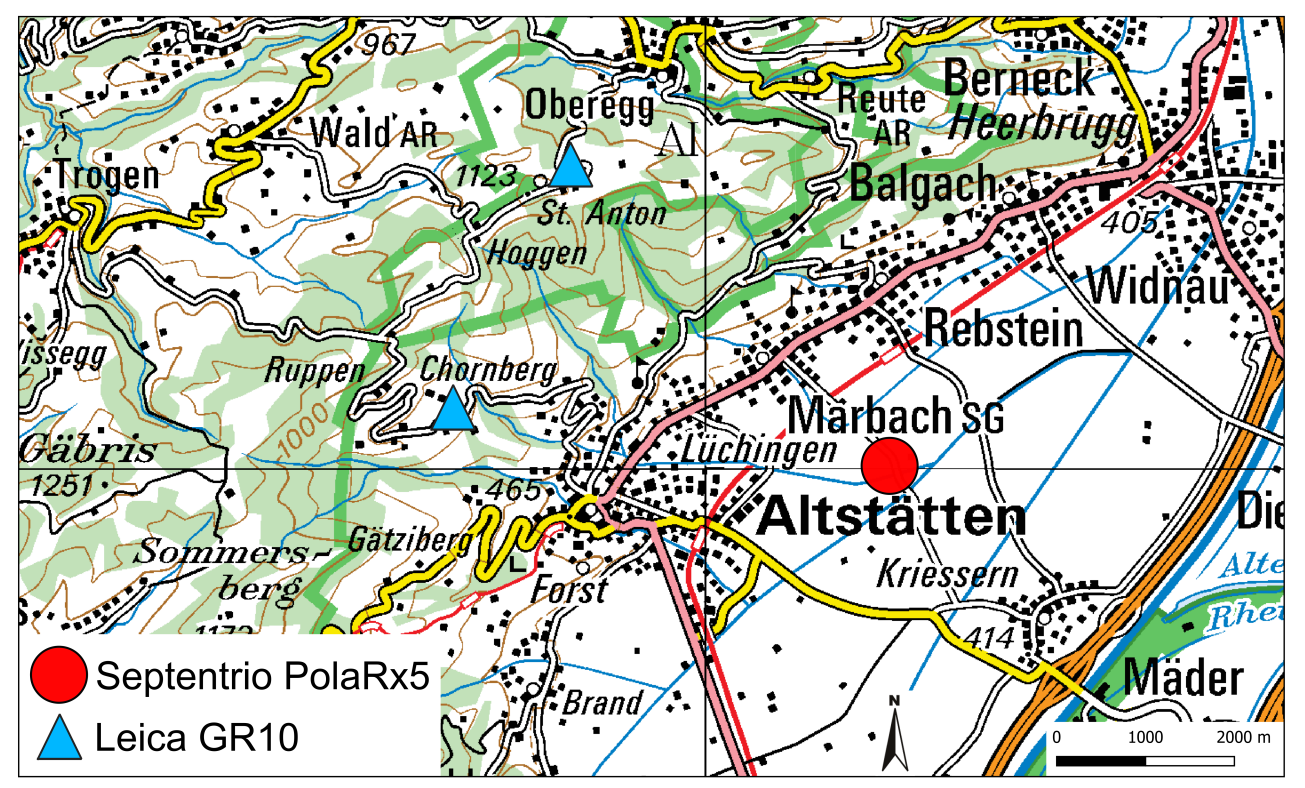

Figure 2: The vicinity of the launch area with the installed GNSS receivers.

at about $1090 \mathrm{~m}$ asl. Moreover, a Septentrio PolaRx5 GNSS receiver was installed at the drone launch site.

Figure 2 shows the location of the temporary stations.

\subsection{The flights}

At first, a test flight was completed to check if the wind at different altitudes allows for carrying out the experiment. During the test, the drone has only reached the altitude of about $2300 \mathrm{~m}$ asl due to a strong wind (more than $10 \mathrm{~m} / \mathrm{s}$ ) encountered at that height. Afterwards, eight flights were performed, with only three flights reaching and even slightly exceeding the planned height of $3000 \mathrm{~m}$ above the ground, which corresponds to around $3413 \mathrm{~m}$ asl. Table 2 shows a list of all the flights. The climb rate of the drone at the beginning of the flights was approx. $5.7 \mathrm{~m} / \mathrm{s}$. To assure the safety of the flight despite the wind, the climb rate was temporarily reduced. The average time of one flight was 15-20 minutes. The meteorological parameters and positions were recorded with a sampling rate of $4 \mathrm{~Hz}$ producing from around 3000 observations for the shorter flights to 5000 for the longer flights.

\subsection{GNSS reference stations}

The measurements from the Meteodrone are compared to the interpolation model derived from GNSS data. Figure 3 shows the location of the 32 GNSS stations used to build the model. The following networks from three countries are utilized:

- Temporary stations set up by ETH (CH) (3 stations) 
Table 2: The list of conducted flights during the night of March 28-29, 2019.

\begin{tabular}{llll}
\hline Flight No. & Time UTC & Maximum height & Limitation \\
\hline 1 & $21.51-22.05$ & $2353 \mathrm{~m}$ asl & wind \\
2 & $22.31-22.43$ & $2280 \mathrm{~m}$ asl & wind \\
3 & $22.58-23.10$ & $2185 \mathrm{~m}$ asl & wind \\
4 & $23.22-23.35$ & $2144 \mathrm{~m}$ asl & wind \\
5 & $23.51-00.12$ & $3412 \mathrm{~m}$ asl & - \\
6 & $00.16-00.35$ & $3423 \mathrm{~m}$ asl & - \\
7 & $00.37-00.58$ & $3020 \mathrm{~m}$ asl & wind \\
8 & $01.11-01.32$ & $3407 \mathrm{~m}$ asl & - \\
9 & $01.51-02.12$ & $2974 \mathrm{~m}$ asl & wind \\
\hline
\end{tabular}

- Automated GNSS Network for Switzerland (AGNES) provided by the Swiss Federal Office of Topography (swisstopo) (CH) (12 stations)

- REFNET provided by geotopo $(\mathrm{CH})$ (4 stations)

- Leica Geosystems Network (CH) (3 stations)

- Satellite Positioning Service of the German Surveying (SAPOS) provided by SAPOS-BY and SAPOS$\mathrm{BW}$ (DE) (2 stations)

- Austrian Positioning Service (APOS) provided by Federal Office of Metrology and Surveying (BEV) (AU) (3 stations)

- Echzeit Positionierung Austria (EPOSA) provided by TU-Wien (AU) (4 stations)

- EUREF Permanent GNSS Network provided by TU-Wien (AU) (1 station)

Figure 4 shows the height distribution of the stations. They are located at a variety of heights, from $411 \mathrm{~m}$ asl to $2208 \mathrm{~m}$ asl. The majority of the stations (21) is located below $1000 \mathrm{~m}$ asl. A GPS double difference phase solution with fixed ambiguities was computed for the selected GNSS stations using the Bernese GNSS software version 5.2 (Dach et al., 2015). The ZTDs were modeled as piece-wise linear functions with a sampling of 1 hour. The elevation cut-off angle was set to $3^{\circ}$ and the mapping function was GMF (Global Mapping Function).

\section{Methodology}

We compare the refractivity and $Z T D$ obtained from meteorological measurements from the drone with the interpolated values from the surrounding GNSS stations. In this section, we present the methods of 


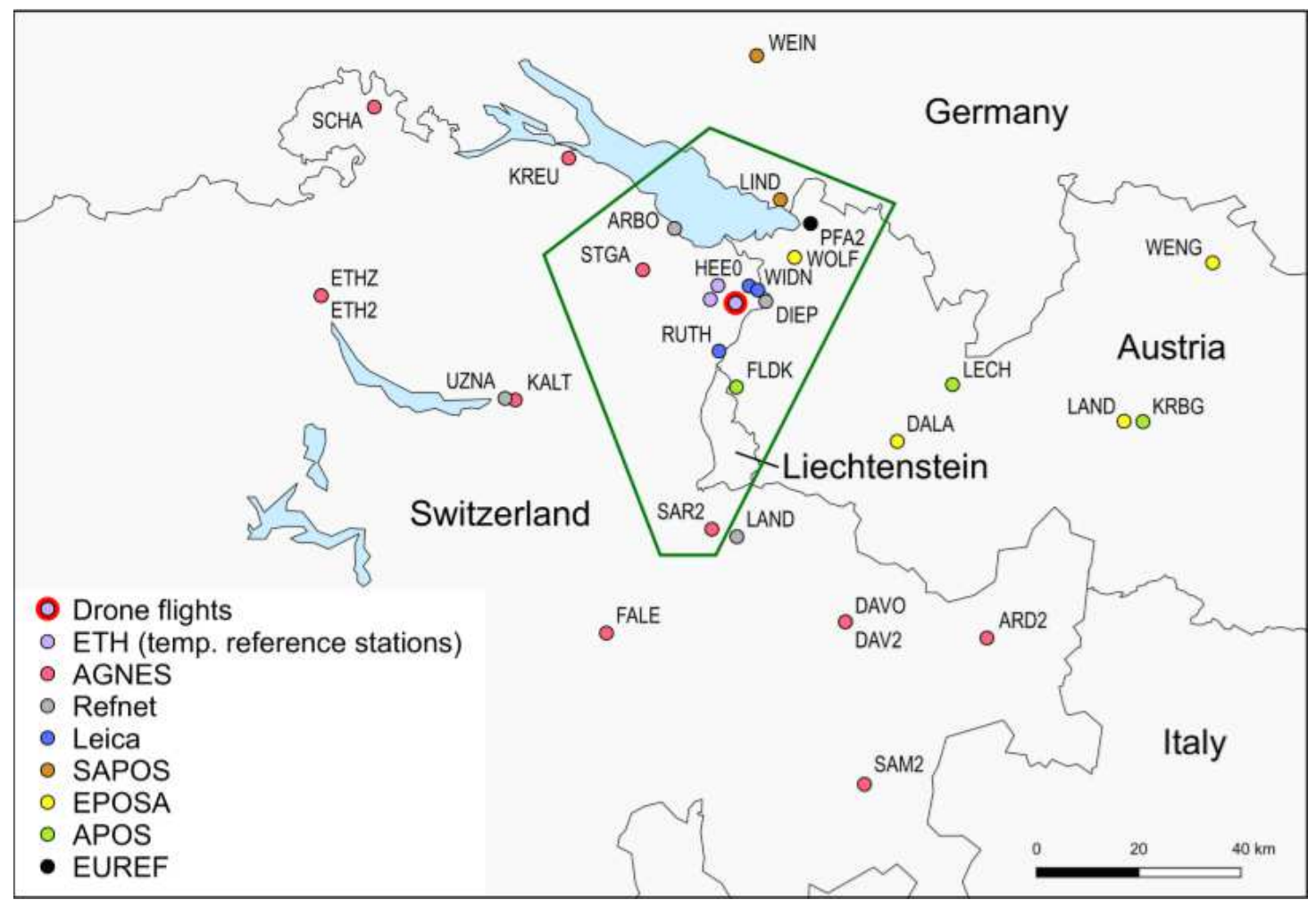

Figure 3: The location of GNSS stations from different networks used to build the interpolation model. The green polygon shows the 14 stations closest to the Meteodrones launch site.

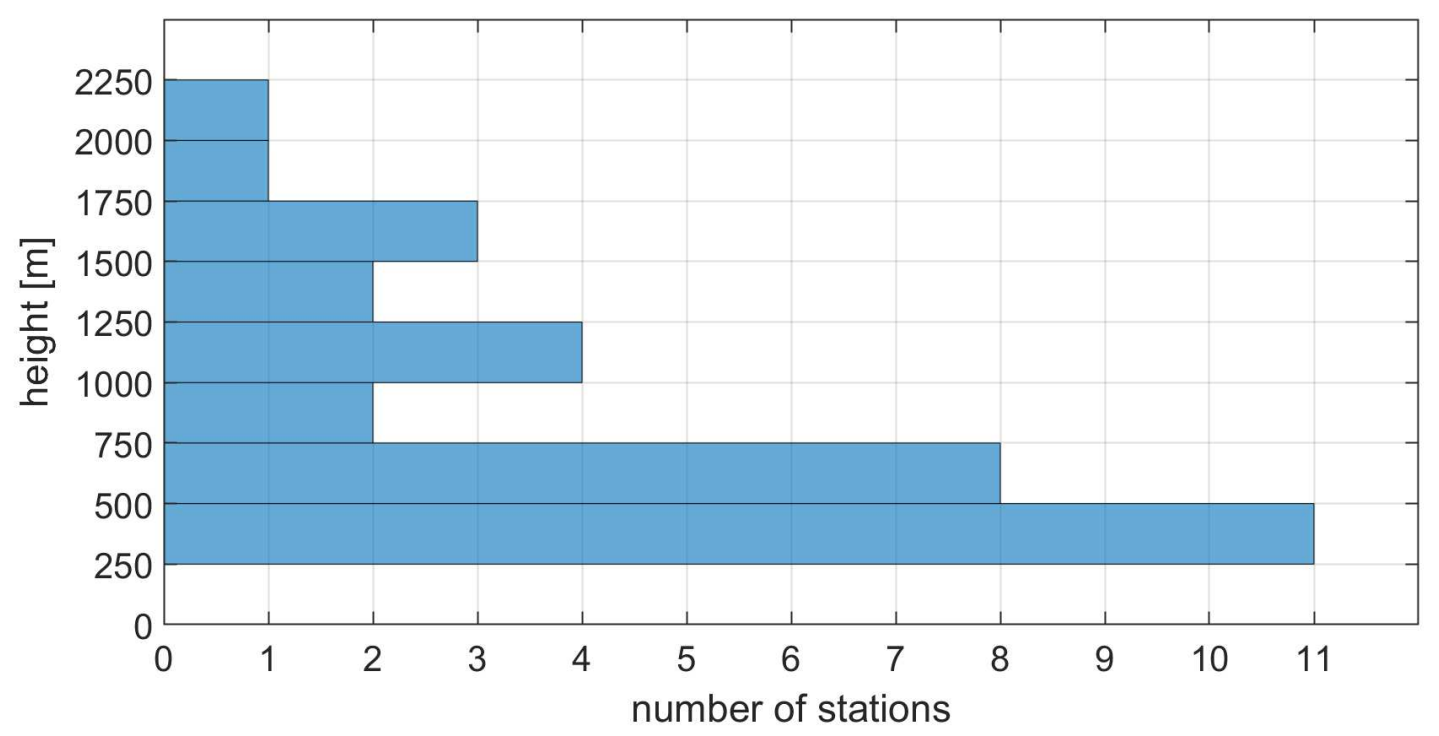

Figure 4: The height distribution of the 32 GNSS stations used in the interpolation model. 
calculating the tropospheric parameters for all the flight levels.

\subsection{Calculation of tropospheric parameters}

The Meteodrones measure temperature $T[\mathrm{~K}]$, air pressure $p[\mathrm{hPa}]$ and relative humidity $R H[\%]$. To calculate the total refractivity $N$ [ppm], the relative humidity must be converted into water vapor partial pressure $e[\mathrm{hPa}]$. Firstly, we calculate the water vapor partial pressure of the saturated air $e_{\text {sat }}$ using the Clausius-Clapeyron formula (Haltiner and Martin, 1957):

$$
e_{s a t}=e_{s a t, 0} \cdot \exp \left[\frac{-L}{R_{v}} \cdot\left(\frac{1}{T}-\frac{1}{T_{0}}\right)\right],
$$

where: $T_{0}=273.13 \mathrm{~K}$ and $e_{s a t, 0}=6.11 \mathrm{hPa}$ are the reference values at $0^{\circ} \mathrm{C} ; R_{v}=461.525 \mathrm{~J} \cdot \mathrm{kg}^{-1} \cdot \mathrm{K}^{-1}$ is the specific gas constant of water vapor and $L$ is either the latent heat of vaporization $\left(L_{1}=2.5 \cdot 10^{6} \mathrm{~J}\right.$. $\mathrm{kg}^{-1}$ for $\left.T>273.15 \mathrm{~K}\right)$ or sublimation $\left(L_{2}=2.834 \cdot 10^{6} \mathrm{~J} \cdot \mathrm{kg}^{-1}\right.$ for $\left.T<273.15 \mathrm{~K}\right)$. Then, we calculate the water vapor partial pressure $e[\mathrm{hPa}]$ from relative humidity $R H[\%]$ as:

$$
e=\frac{R H \cdot e_{s a t}}{100 \%} .
$$

From the temperature, air pressure and water vapor partial pressure, we calculate the total refractivity $N$ [ppm] for each drone measurement (Essen and Froome, 1951):

$$
N=k_{1} \cdot \frac{p_{d}}{T} \cdot Z_{d}^{-1}+k_{2} \cdot \frac{e}{T} \cdot Z_{w}^{-1}+k_{3} \cdot \frac{e}{T^{2}} \cdot Z_{w}^{-1}
$$

where $p_{d}=p-e$ is the dry air pressure; $Z_{d}^{-1}$ and $Z_{w}^{-1}$ are the dry and wet compressibility factors and are usually set to one; $k_{1}=77.689 \frac{\mathrm{K}}{\mathrm{hPa}}, k_{2}=71.295 \frac{\mathrm{K}}{\mathrm{hPa}}$ and $k_{3}=375463 \frac{\mathrm{K}^{2}}{\mathrm{hPa}}$ are the refractivity constants, in this study taken from Rüeger (2002) as 'best average'. From the refractivity at each level, we calculate the ZTD as:

$$
Z T D=10^{-6} \cdot \int_{z_{d}}^{\infty} N(h) d z .
$$

where $z_{d}$ is the orthometric height of the drone at the observation. Eq. 4 can be written in a discrete form as:

$$
Z T D \approx 10^{-6} \cdot \sum_{i=1}^{t o p-1}\left(\frac{N_{i}+N_{i+1}}{2}\right) \cdot \Delta z_{i},
$$

where $\Delta z_{i}$ is the height difference between $i$-th and $(i+1)$-th level and top is the uppermost level of the drone measurement. Thus, the delay is not calculated for the entire troposphere, but from the chosen level (starting at the ground) to the top level. 


\subsection{Interpolation of GNSS data}

The GNSS zenith path delays are interpolated at the location of drone measurements using the leastsquares collocation software COMEDIE developed at ETH Zurich (Eckert et al., 1992a,b; Troller, 2004; Hurter and Maier, 2013; Wilgan et al., 2017a). The collocation technique divides each measurement into a deterministic part (trend), a correlated stochastic (signal), and uncorrelated stochastic part (noise). Using the input data, the parameters of the trend are estimated in the least-square sense. For the ZTD, we use the following formula describing the deterministic model:

$$
Z T D(x, y, z, t)=\left[Z T D_{0}+a\left(x-x_{0}\right)+b\left(y-y_{0}\right)+c\left(t-t_{0}\right)\right] \cdot e^{-\frac{z-z_{0}}{H_{0}}},
$$

where $x, y, z, t$ are the Swiss projected coordinates $\mathrm{LV}_{03}{ }^{1}$, orthometric height and time of the investigated point; $x_{0}, y_{0}, z_{0}=0, t_{0}$ are the projected coordinates, height and time of the reference point. In case it is not defined, the reference point is calculated in the collocation procedure as an average from all input points for each time batch. The $Z T D_{0}$ is the $Z T D$ at the reference position and time $t_{0}, H_{0}$ is the scale height and $a, b, c$ are the gradient parameters in $x, y$ and time, respectively. The parameters $Z T D_{0}, H_{0}, a, b, c$ are the unknowns in the collocation procedure and are estimated for each time batch.

The signal is assumed to be normally distributed with mean zero and the covariance matrix $C_{s s}$ depending on the distances between the measurements. The covariance function for ZTD is chosen to be:

$$
C_{s s}(i, j)=\frac{\sigma_{\text {signal }}^{2}}{1+\left[\left(\frac{x_{i}-x_{j}}{\Delta x_{0}}\right)^{2}+\left(\frac{y_{i}-y_{j}}{\Delta y_{0}}\right)^{2}+\left(\frac{z_{i}-z_{j}}{\Delta z_{0}}\right)^{2}+\left(\frac{t_{i}-t_{j}}{\Delta t_{0}}\right)^{2}\right] \cdot e^{-\frac{z_{i}+z_{j}}{2 z_{0}}}}
$$

where $\sigma_{\text {signal }}^{2}$ is the a-priori variance of the signal, $x_{i}, y_{i}, z_{i}, t_{i}$ are the projected Swiss coordinates, orthometric height, and time of observation $i ; x_{j}, y_{j}, z_{j}, t_{j}$ are the coordinates, height and time of observation $j ; z_{0}=4 \mathrm{~km}$ is the parameter modifying the correlation lengths as a function of height; $\Delta x_{0}=50 \mathrm{~km}$, $\Delta y_{0}=50 \mathrm{~km}, \Delta z_{0}=1 \mathrm{~km}, \Delta t_{0}=1.7 \mathrm{~h}$ are the empirically determined correlation lengths of space and time.

The GNSS-based ZTDs are calculated for each level of the Meteodrone flights. The delays from the drone are only partial, calculated until the uppermost level of the drone flight. Thus, we also calculate only the partial delays from the GNSS data. For that we subtract the GNSS ZTDs interpolated at the top level from the delays for the lower levels.

Since the $Z T D$ is an integral of total refractivity (Eq. 4), the deterministic model for $N$ can be obtained by applying a differential operator $D=\frac{-\partial}{\partial z}$ to Eq. 6 , yielding the deterministic model of refractivity:

$$
N(x, y, z, t)=\frac{1}{H_{0}}\left[Z T D_{0}+a\left(x-x_{0}\right)+b\left(y-y_{0}\right)+c\left(t-t_{0}\right)\right] \cdot e^{-\frac{z-z_{0}}{H_{0}}}
$$

\footnotetext{
${ }^{1}$ https://www.swisstopo.admin.ch/en/knowledge-facts/surveying-geodesy/reference-frames/local/lv03.html
} 
To derive the covariance functions between $N$ and $Z T D$ as well as between two refractivity measurements, the operator $D$ is applied to the covariance function of $Z T D$ (Eq. 7). For more detail, please refer to Wilgan et al. (2017a) or Hurter and Maier (2013).

\section{Results}

In this section, we present the comparison of the retrieval of tropospheric parameters by the drone measurements and by the interpolation model from GNSS. The emphasis is on the ZTD and total refractivity retrievals. At first, we show the meteorological parameters measured by the drone.

\subsection{Meteorological measurements from the drone}

The Meteodrone measures profiles of the meteorological parameters in both ascending and descending mode. Figure 5 shows the unprocessed measurements of temperature, pressure and relative humidity, respectively, linearly interpolated in between flights for better visualization. The dashed red lines represent the nine drone flights.

Figure 5 shows a shift in the temperature measurements for the same flight and height between the ascending and descending drone. At the same height, the ascending temperature is higher by around 0.5$1 \mathrm{~K}$ than the measured temperature during the descend. This can be a result of a down-cooling of the drone in the higher altitudes. Moreover, a thin layer of air directly above the ground is a few degrees colder than the layer above. Furthermore, from the 5th flight onward, a layer of warmer air has formed at about $2250 \mathrm{~m}$, while directly below and above the temperature was lower. For air pressure, there are small differences between the ascending and descending values, but overall, a very homogeneous, stratified pressure distribution is observed. For relative humidity, a layer with higher humidity is visible close to the ground. In the course of the experiment, the humidity in the higher air layers steadily decreases. Although, below $2000 \mathrm{~m}$, individual small cells are recognizable, which contain humidity of over $60 \%$. Since the humidity values fluctuate a lot, a differences between the ascend and descend are not so clearly distinguishable as in the case of temperature. Although, close to the ground, the humidity values from the descending drone are usually higher than for the ascending flight. A similar situation is also visible above $2000 \mathrm{~m}$ asl, but with much smaller humidity discrepancies.

Meteomatics provides also the processed data, where all the observations for each flight are reduced to one time (the median time of the flight). The hysteresis between the ascending and descending flight is eliminated. Figures 6 shows the temperature, air pressure and relative humidity, respectively from the processed observations.

In the processed observations, shown in Figure 6, the main features of the weather conditions for the flights are much better delineated. During the night, the temperature is cooling down close to the ground 

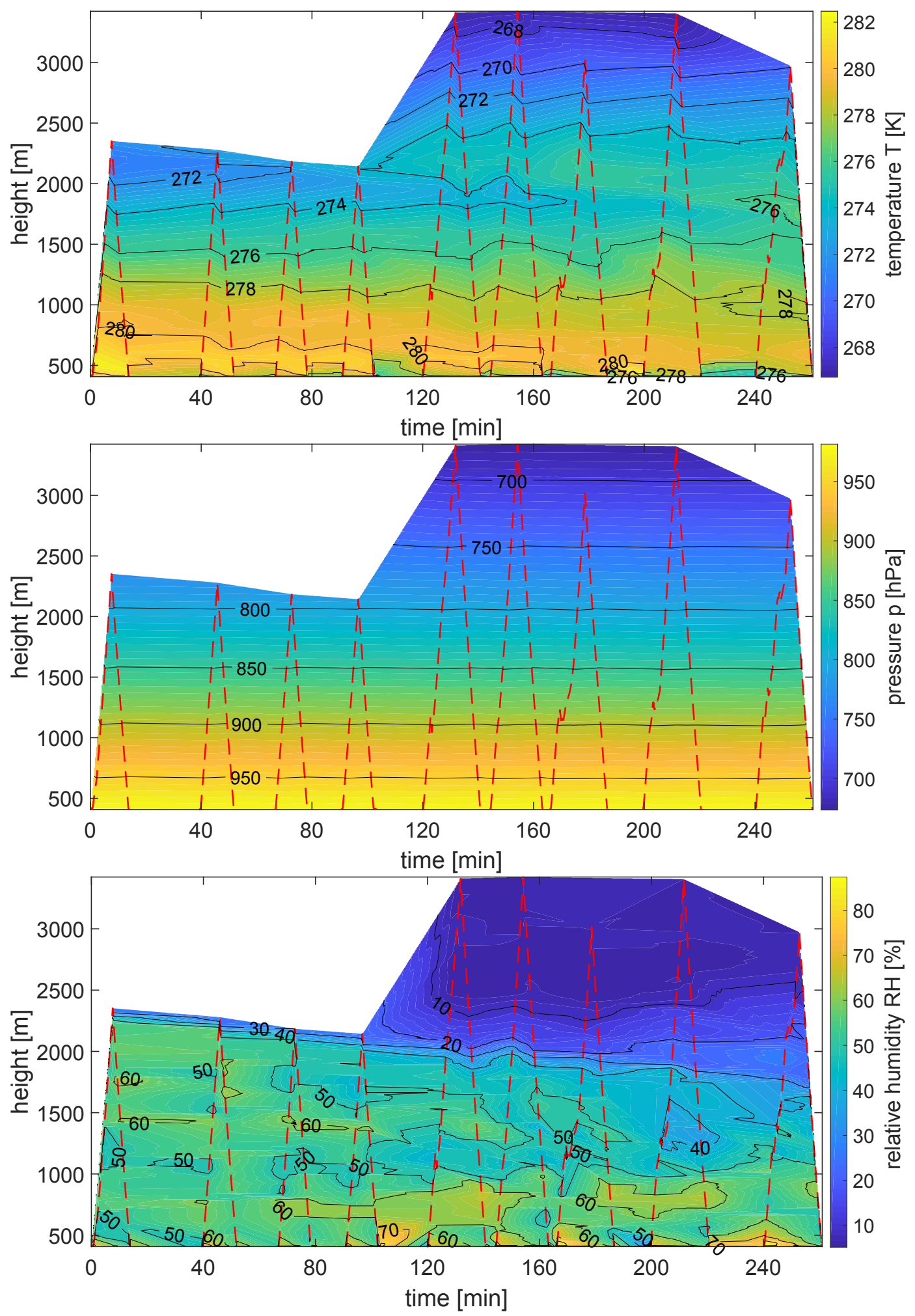

Figure 5: The raw measurements of temperature (top), air pressure (middle) and relative humidity (bottom) by the drone interpolated between the flights. Red dashed lines indicate the time of the flights. The flights took place during the night of March 28 - 29, 2019. 

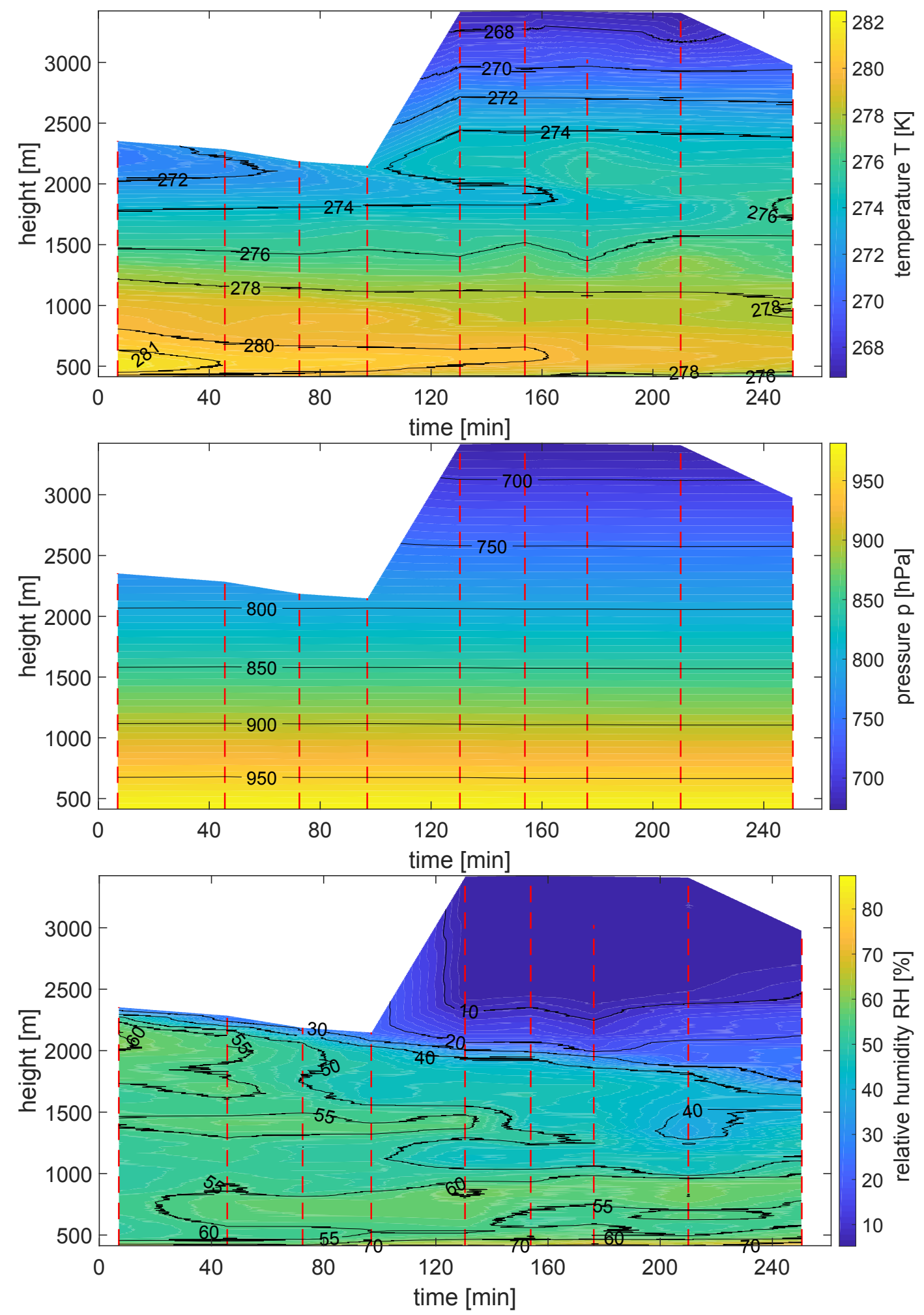

Figure 6: The processed measurements of temperature (top), air pressure (middle) and relative humidity (bottom) by the drone interpolated between the flights. Red dashed lines indicate the time of the flights. The flights took place during the night of March 28 - 29, 2019. 


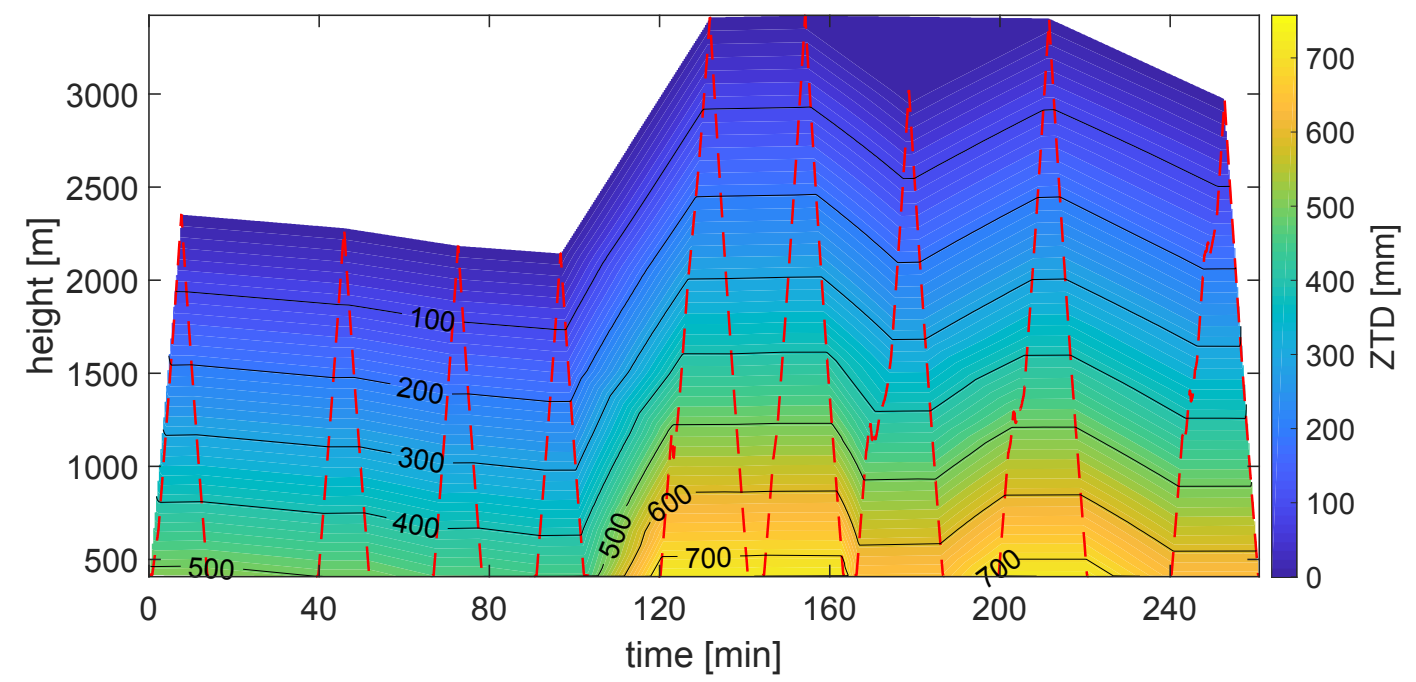

Figure 7: The ZTD calculated from the raw meteorological measurements by the drone. Red dashed lines indicate the time of the flights. The flights took place during the night of March $28-29,2019$.

due to the mostly uncovered sky. However, there is a rise of temperature with simultaneous decrease of humidity at around $2000 \mathrm{~m}$ asl. This is due to an inflow of foehn-type of air from southern direction. This wind is also the cause of the shear zone at around $2000 \mathrm{~m}$ which has clearly sunk by about $200 \mathrm{~m}$ during the night (Figure 6, bottom). The air pressure distribution remains very stratified, depending only on the height.

\subsection{Comparison of tropospheric parameters}

We calculate the $Z T D$ s from the raw meteorological drone measurements according to Eq. 5 . Figure 7 shows the values of $Z T D$. Please note that the maximum values are at a level of $700 \mathrm{~mm}$, which is due to the fact that we calculate only the partial delays from the ground to the highest altitude of the drone.

Figure 8 shows the differences between $Z T D_{M}$ from the drone and $Z T D_{G N S S}$ interpolated from the path delays determined at neighboring GNSS stations. To make the $Z T D_{G N S S}$ comparable with $Z T D_{M}$, we also calculated partial $Z T D_{G N S S}$ described in Section 3.2.

As shown in Figure 8, the values of $Z T D_{G N S S}$ are in general smaller than the $Z T D_{M}$ from the drone, especially closer to the surface. Only, during the 5 th flight, at a height of about $2000 \mathrm{~m}$, there is an instance when $Z T D_{M}$ is smaller. During the last two flights, significant differences close to the ground occur. The maximum difference is $14.4 \mathrm{~mm}$ and the minimum is $-3.3 \mathrm{~mm}$. On average, the absolute differences are around $2.8 \mathrm{~mm}$. Furthermore, we calculated the differences between the processed drone observations and the GNSS interpolation model. Figure 9 shows these differences.

Figure 9 shows similar results to Figure 8: during the 5th flight, at a height of approximately $2000 \mathrm{~m}$, there is an instance, where the $Z T D_{G N S S}$ is larger than the $Z T D_{M}$. Moreover, from a time of 200 minutes 


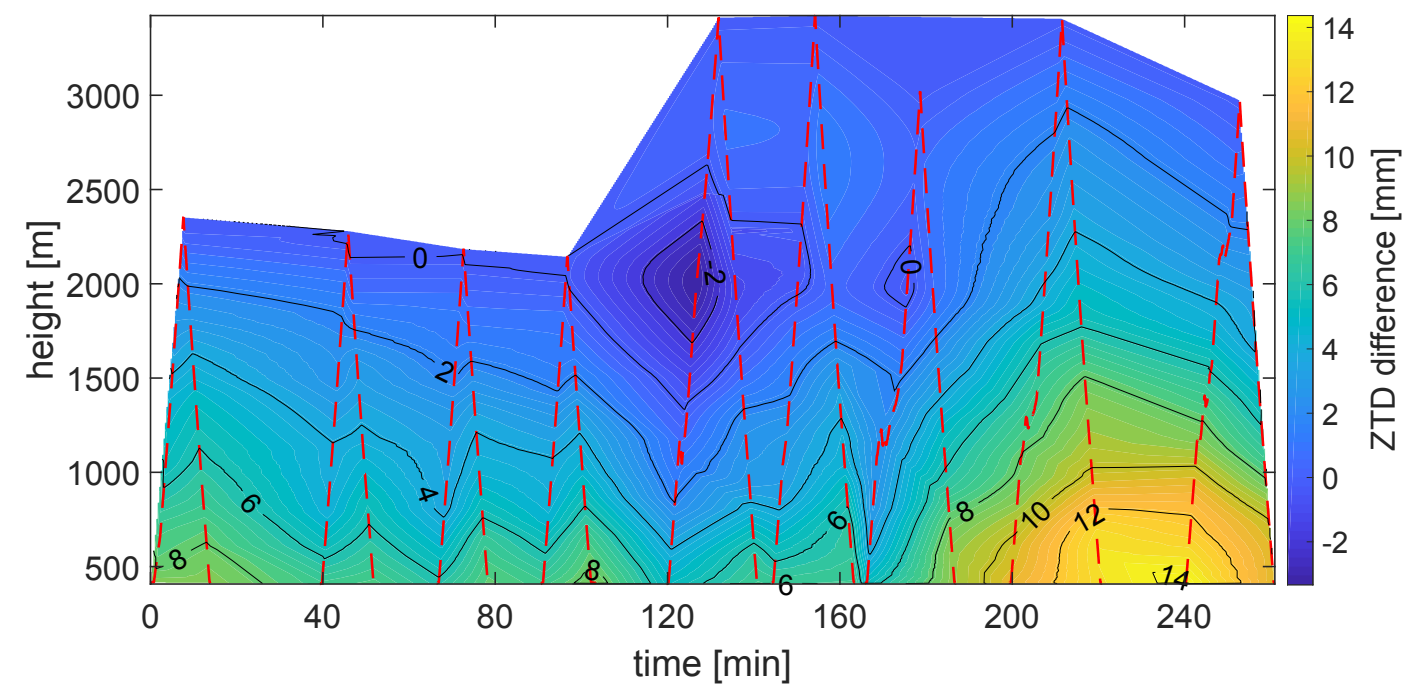

Figure 8: The differences between $Z T D_{M}$ from raw measurements and $Z T D_{G N S S}$. Red dashed lines indicate the time of the flights. The flights took place during the night of March 28 - 29, 2019.

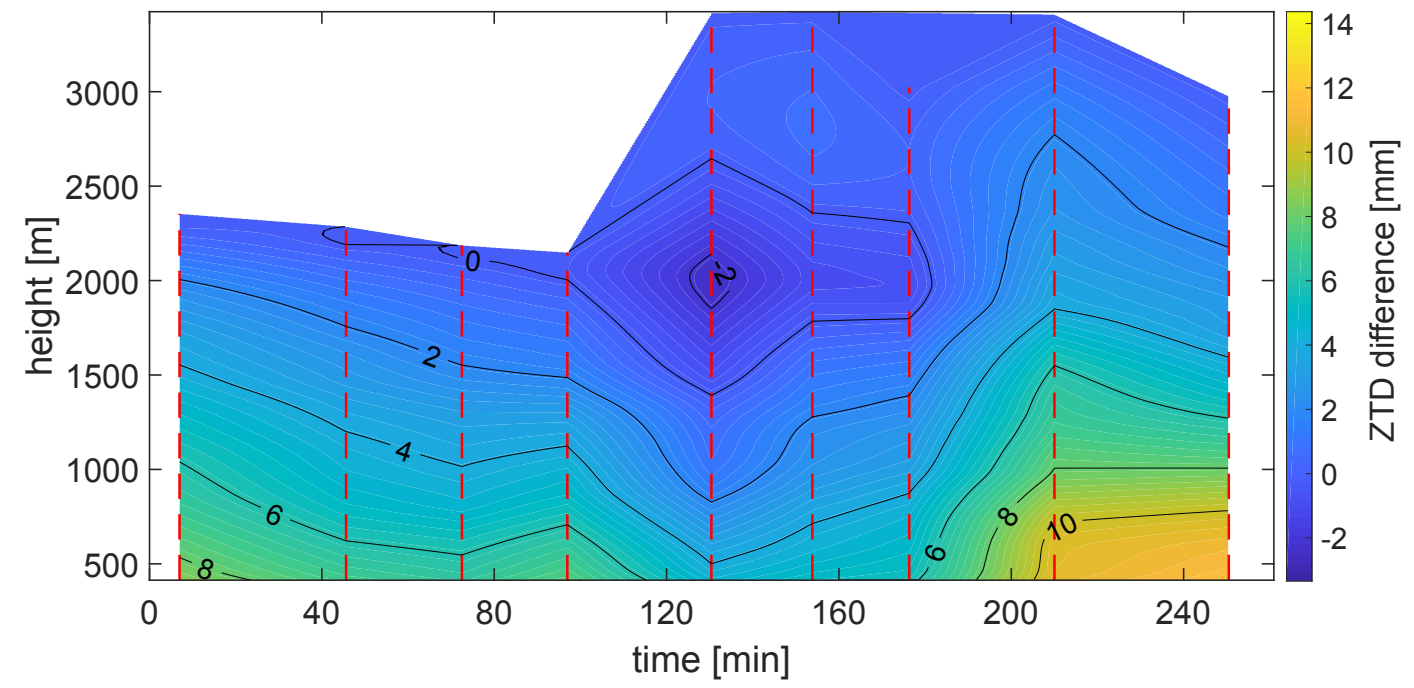

Figure 9: The differences between $Z T D_{M}$ from the processed measurements and $Z T D_{G N S S}$. Red dashed lines indicate the time of the flights. The flights took place during the night of March $28-29,2019$. 


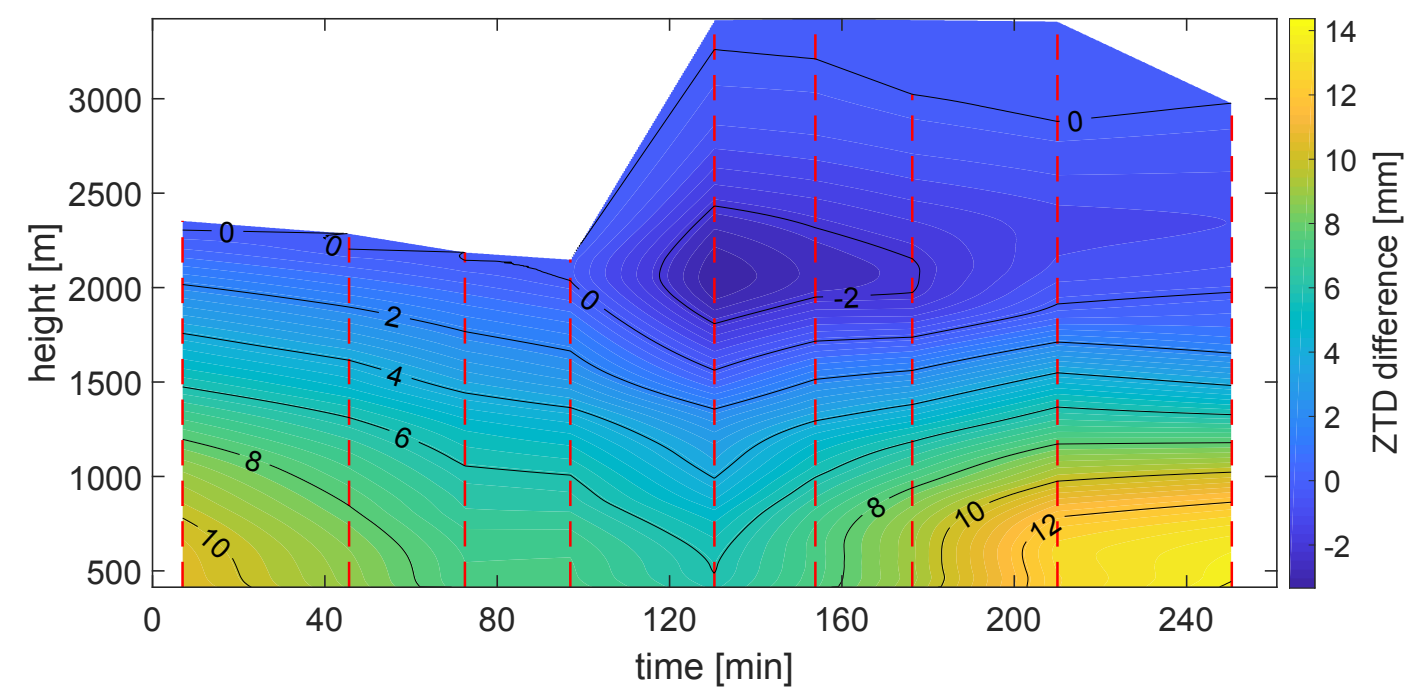

Figure 10: The differences between $Z T D_{M}$ from the processed measurements and $Z T D_{G N S S}$ from 14 stations. Red dashed lines indicate the time of the flights. The flights took place during the night of March $28-29,2019$.

the largest differences are observed, although, they are smaller than for the raw measurements. The absolute differences are on average $2.8 \mathrm{~mm}$. The maximum value is $11.7 \mathrm{~mm}$ and the minimum is $-2.4 \mathrm{~mm}$.

There are 32 GNSS stations used in the interpolation model. We test how the solution changes, if we incorporate less GNSS stations into the model. Figure 10 shows the differences between the $Z T D_{M}$ and $Z T D_{G N S S}$ calculated only from the 14 stations closest to the drone launch site (maximum distance less than $40 \mathrm{~km}$ ). The selection of the stations is shown in Figure 3 as a green polygon. The stations located in the closest vicinity of the launch site do not have a diversified height resolution as all of the stations. Out of the 14 stations used, 11 are located below $1000 \mathrm{~m}$ asl. The highest stations in this data set are: the AGNES station Sargans SAR2 (located at $1217 \mathrm{~m}$ asl), the EUREF station Bregenz PFA2 (1043 m asl) and the temporary station on the St. Anton Pass (1090 m asl).

The model calculated from 14 stations has slightly larger differences closer to the ground compared to the $Z T D_{M}$ than the model based on 32 stations. The maximum difference for the 14 -stations model is 14.1 $\mathrm{mm}$, the minimum is $-3.2 \mathrm{~mm}$ and the average absolute difference is $3.1 \mathrm{~mm}$. For the higher altitudes, the differences between the $Z T D_{M}$ and $Z T D_{G N S S}$ from 14 stations are close to 0 or even negative compared to the model from all the stations. Figure 11 shows the differences and standard deviations between $Z T D_{M}$ and $Z T D_{G N S S}$ from all three methods averaged over time, and Table 3 shows the absolute mean, minimum and maximum values of the differences and the standard deviations averaged over all the heights and time.

All of the methods behave very similarly: they all exhibit bias, especially due to the differences in the lower levels, close to the ground. All of the methods have also very small standard deviations, below $2 \mathrm{~mm}$. The lowest standard deviation, of only $1.2 \mathrm{~mm}$, results from the comparisons of $Z T D_{M}$ with $Z T D_{G N S S}$ from 


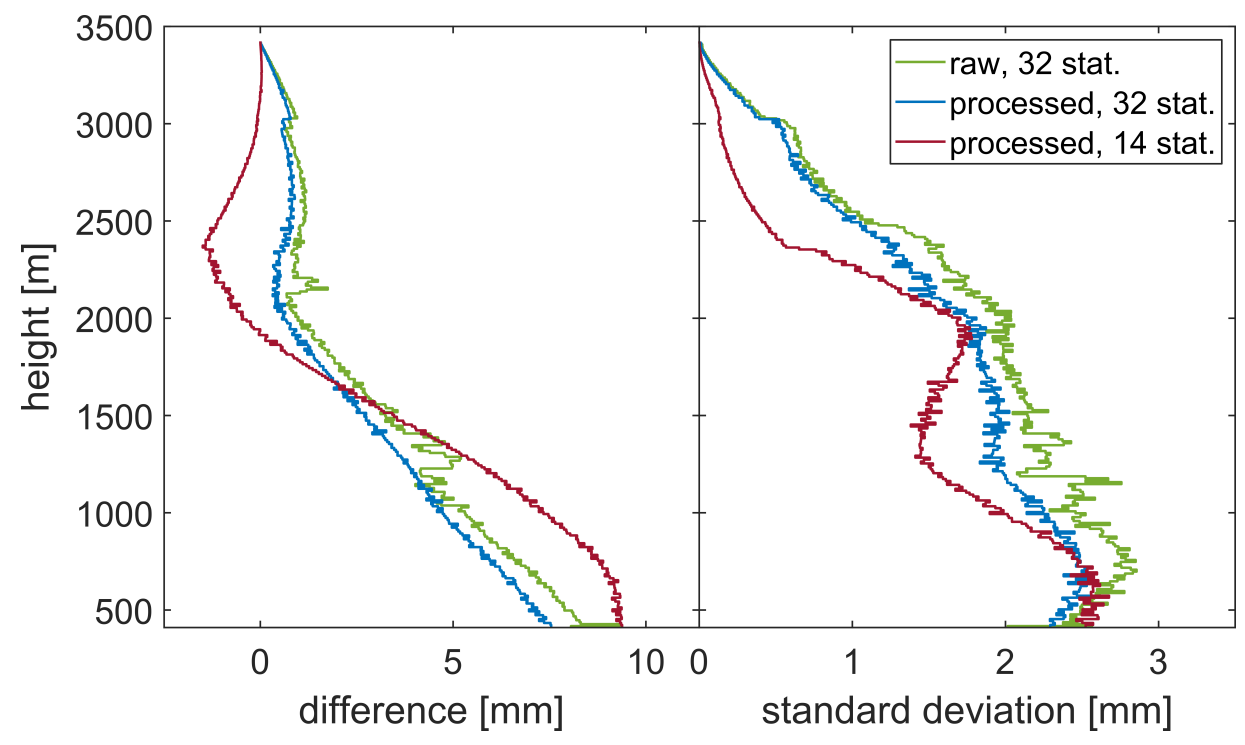

Figure 11: The differences and standard deviations between $Z T D_{M}$ and $Z T D_{G N S S}$ from all three methods averaged over time (March 28 - 29, 2019).

Table 3: The mean absolute bias, the minimum and maximum value of the differences and standard deviations between $Z T D_{M}$ and $Z T D_{G N S S}$ from all three methods averaged over all the heights and time (March 28 - 29, 2019).

\begin{tabular}{lllll}
\hline method & $\begin{array}{l}\text { absolute bias } \\
{[\mathrm{mm}]}\end{array}$ & $\begin{array}{l}\text { min. difference } \\
{[\mathrm{mm}]}\end{array}$ & $\begin{array}{l}\text { max. difference } \\
{[\mathrm{mm}]}\end{array}$ & $\begin{array}{l}\text { standard deviation } \\
{[\mathrm{mm}]}\end{array}$ \\
\hline raw, 32 stations & 2.8 & -3.3 & 14.4 & 1.7 \\
processed, 32 stations & 2.4 & -2.4 & 11.7 & 1.5 \\
processed, 14 stations & 3.1 & -3.2 & 14.1 & 1.2 \\
\hline
\end{tabular}




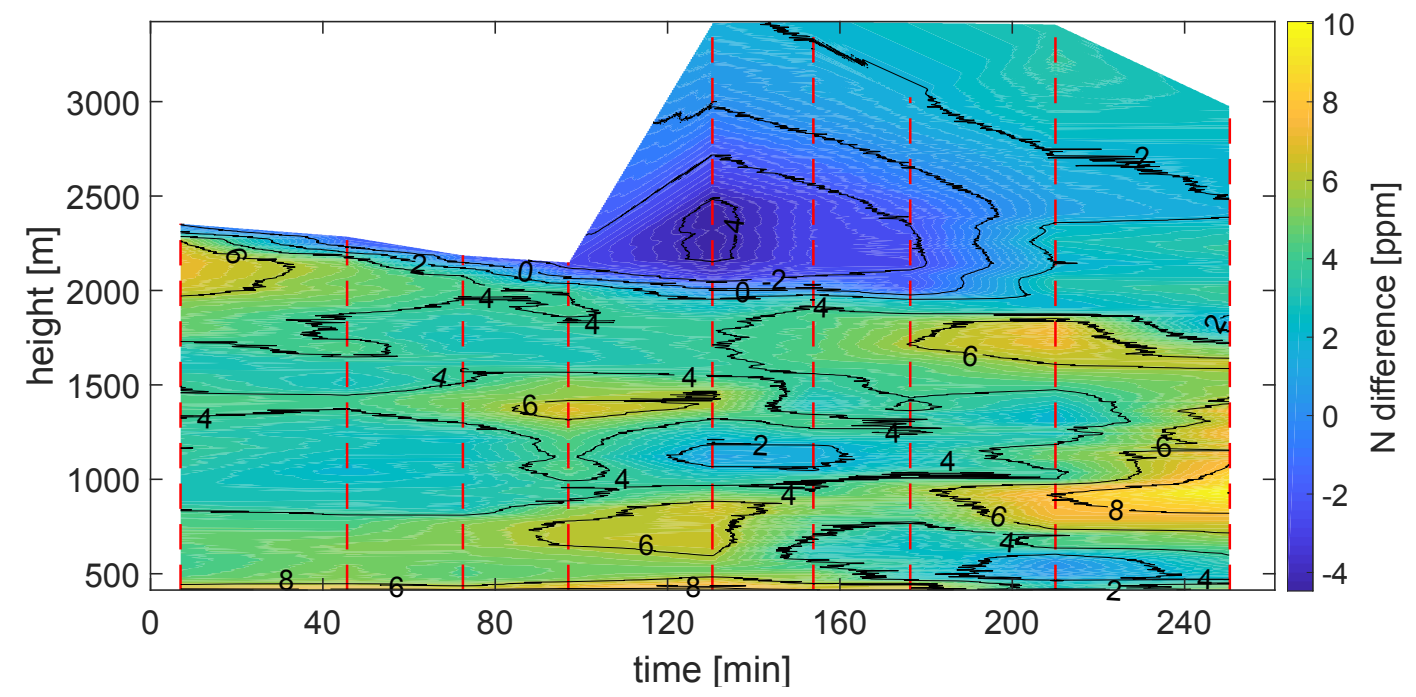

Figure 12: The differences between $N_{M}$ from the processed measurements and $N_{G N S S}$. Red dashed lines indicate the time of the flights. The flights took place during the night of March 28 - 29, 2019.

14 stations, and is especially low compared to the other methods at altitudes of 1000 and $2500 \mathrm{~m}$ asl. The bias for 14 stations is higher close to the ground and becomes negative above the height of $2000 \mathrm{~m}$ asl. This may be due to the less varying height distribution of the surrounding stations. The $Z T D_{G N S S}$ models from 32 stations have very similar statistics for both raw and processed observations. Thus, for the comparisons of total refractivity we use only the model from 32 stations and processed Meteodrone measurements.

We compare the total refractivity values from the drone and GNSS data. The refractivity $N_{M}$ from the $p, T$, e measurements on the drone is calculated for all the height levels using Eq. 3. The GNSS refractivity $N_{G N S S}$ is interpolated from the zenith path delays of the surrounding stations using Eq. 8. This equation allows us to connect the refractivity with the ZTDs obtained from GNSS measurements. Figure 12 shows the differences between $N_{M}$ from the Meteodrone and $N_{G N S S}$ from the interpolation model.

Up to the height of about $2000 \mathrm{~m}$ asl, the total refractivity from the drone measurements is usually larger than the value interpolated from GNSS. Only during the 5th flight, above the height of $2250 \mathrm{~m}$, the $N_{G N S S}$ is larger. This is also the place where the $Z T D_{G N S S}$ is larger than $Z T D_{M}$. The largest refractivity differences occur for 8th and 9th flight at a height of around $1000 \mathrm{~m}$. This is also visible in the comparisons of $Z T D \mathrm{~s}$, but because $Z T D$ is an integrated value, the large differences occur already close to the surface. The average differences from all the flights w.r.t. the height and the associated standard deviations are shown in Figure 13.

In the previous studies (Perler et al., 2011; Hurter and Maier, 2013; Wilgan et al., 2017a; Wilgan and Geiger, 2019) comparing the radiosonde and GNSS data, the differences between the two data sources formed an 'S-shape'. In Wilgan and Geiger (2019), we compared the GNSS-based interpolation model with 


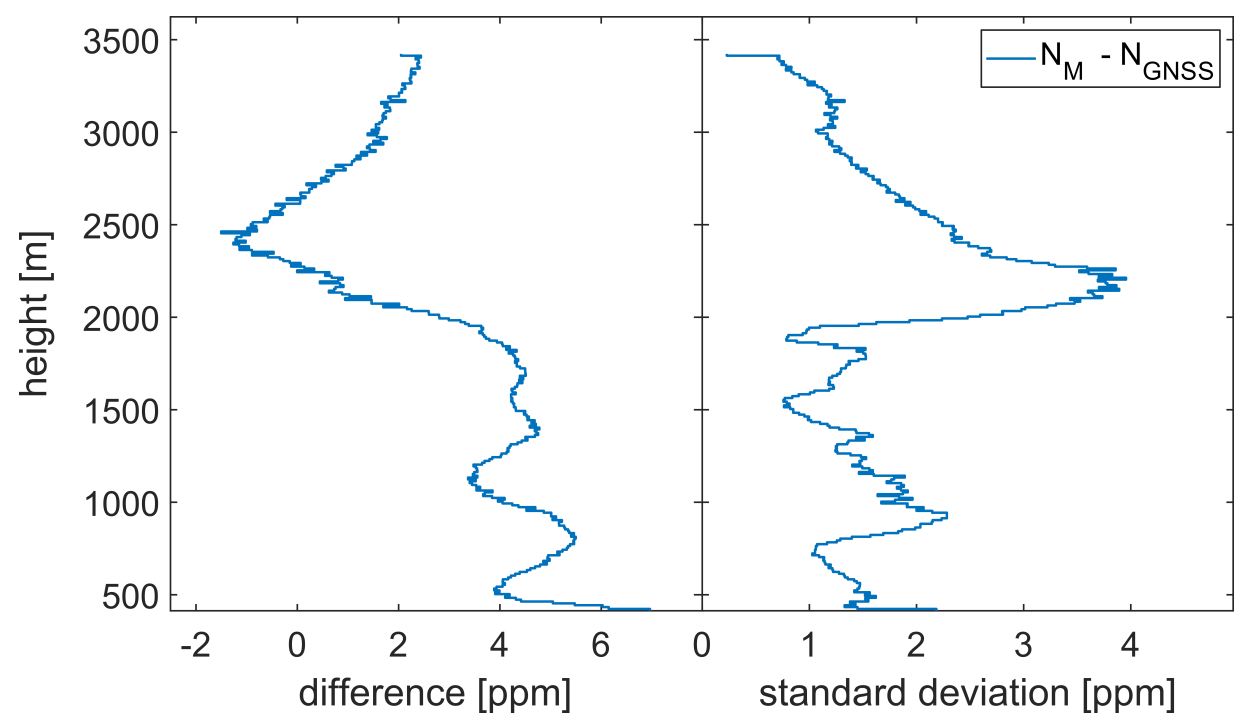

Figure 13: The differences and standard deviations between $N_{M}$ from the processed data and $N_{G N S S}$ averaged over time (March $28-29,2019)$.

the radiosonde data in Payerne, Switzerland. The average bias calculated from two summer months of data, up to the height of $13 \mathrm{~km}$ asl was $2.6 \mathrm{ppm}$ with $5.1 \mathrm{ppm}$ standard deviation. Considering only the heights up to $3.5 \mathrm{~km}$ asl, which corresponds to the top altitude of the drone flight, the average absolute bias was of $5 \mathrm{ppm}$ with $8 \mathrm{ppm}$ standard deviation. For this study, the absolute bias is equal to $2.7 \mathrm{ppm}$ with $1.7 \mathrm{ppm}$ standard deviation. The standard deviation for this study is very small, especially close to the surface and at lower altitudes. Above the height of $2000 \mathrm{~m}$ asl, we acquired less data due to the strong wind, thus the standard deviation increases slightly for this region. As shown in Figure 13, the differences also follows the 'S-shape' but not to the same extent as in the previous studies. We can conclude, that it is an improvement comparing to the previous study, although there remains a bias. The possible reasons for the bias are discussed in the next section.

\section{Discussion}

The agreement between the tropospheric parameters from the drone and from the surrounding GNSS stations is overall very good. The main reason is that we built the interpolation model based on many GNSS stations located at various heights with some of the stations located very close to the experiment site. Although, there are instances where the agreement is poorer, especially at the lower altitudes for flights 8th and 9th. In this section, we propose an explanation for the worse agreement.

We consider that the differences between the techniques are a consequence of very local meteorological conditions that are measured by the Meteodrone, but cannot be captured by the interpolation model. We take a look at the patterns of the changes of temperature, relative humidity and also wind speed. The 


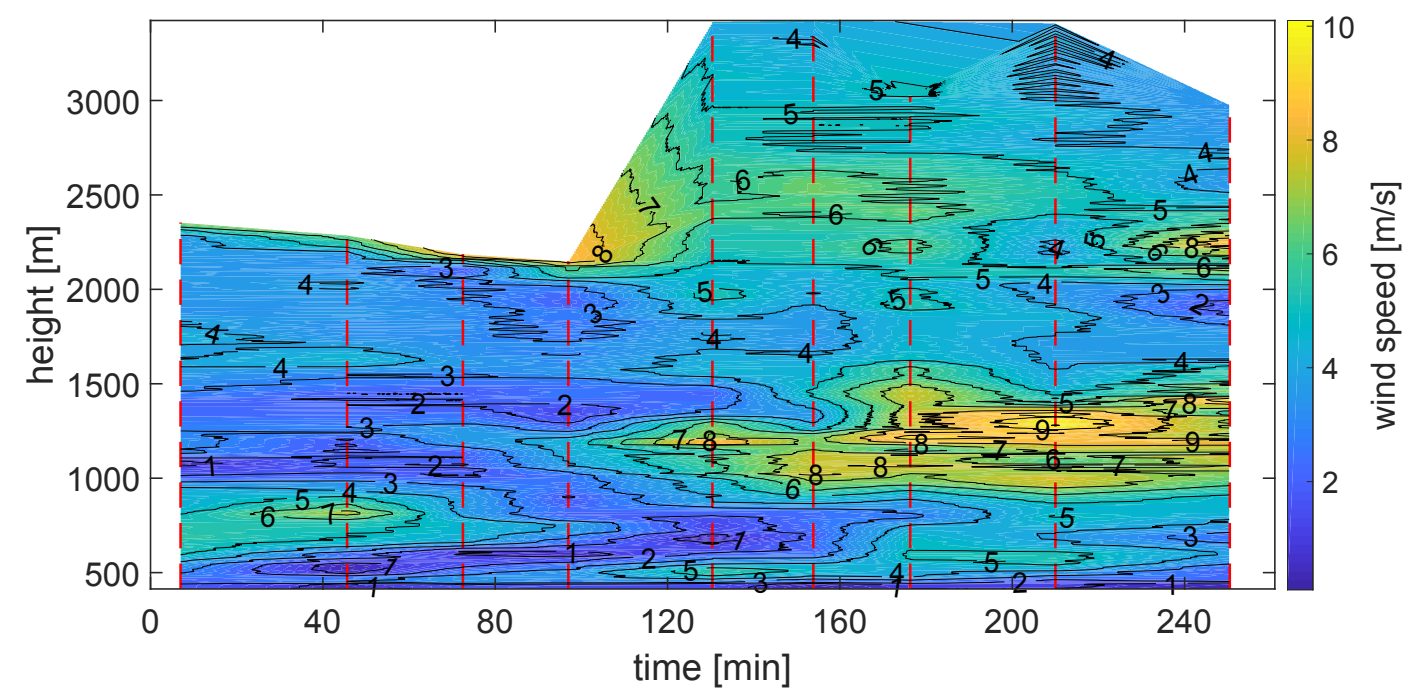

Figure 14: Wind speed for the processed levels of the drone flight. Red dashed lines indicate the time of the flights. The flights took place during the night of March 28 - 29, 2019.

air pressure is uniformly depending on the height and does not show any local features. Figure 14 shows the wind speed, also measured by the drone. Shown before, Figures 5 and 6 present the temperature and relative humidity. According to Eq. 3, in a very simplified way, we may say that an increase of temperature causes a decrease of the total refractivity, while an increase of water vapor partial pressure (proportional to the relative humidity) causes an increase of the total refractivity.

We discuss the differences of total refractivity, because the differences of ZTD are a direct result of the integration of the refractivity. The most significant differences occur:

- Close to the ground for 1st - 7th flights: for this region there is a decrease in temperature, which is no longer visible for flights 8 th - 9th. For the two latter flights, there is also an increase in the relative humidity, but there is no respective change in the differences.

- At altitudes 500 - $1500 \mathrm{~m}$ asl for flights 7 th - 9th: there is a significant increase of wind speed matching these changes, there is also a slight increase of temperature.

- At altitudes 1500 - $2000 \mathrm{~m}$ asl for flights 7 th - 9th: there is a relative humidity decrease, although there are no other significant changes in other parameters.

- At altitudes 500 - $1000 \mathrm{~m}$ asl for flights 4 th - 5th: there is an increase in relative humidity (visible especially in the raw measurements).

- At altitudes 1000 - $1500 \mathrm{~m}$ asl for flights 4 th - 5th: around these heights, the wind speed starts to increase significantly. 
- At altitudes 2000 - $2500 \mathrm{~m}$ asl for the 1st flight: the wind speed increased so significantly, that the flight was no longer possible.

- The negative difference for flight 5 th at altitude of $2250 \mathrm{~m}$ asl: there is a significant temperature increase and then decrease for that flight at this height, which may explain why the difference is so local. There is a very clear line of change in the relative humidity values between 2000 and $2500 \mathrm{~m}$.

Most of the refractivity differences between the drone and GNSS models can be explained by local variations of meteorological parameters. Although, not all of the differences between refractivities are articulated in the differences between $Z T D$ s. The largest $Z T D$ differences are found for the first and the two last flights for the altitudes up to about $1000 \mathrm{~m}$ asl, which may be a result of accumulated differences of refractivity. Although, there are also differences in the refractivity for flights 4 th and 5th that do not correspond with large differences of $Z T D$ for these flights. This may be due to the fact that for these flights there are positive differences of refractivity in the lower altitudes and negative above $2000 \mathrm{~m}$ which may have canceled out in the $Z T D$ differences as a result of an integration.

The plan for this study was to also obtain the tropospheric GNSS estimates directly from the drone using the Bernese GNSS software version 5.2. The drone was equipped with a low-cost dual frequency u-blox ZED-F9P GNSS receiver and ANN-MB antenna. A double difference solution should be determined between the u-blox ZED-F9P on the drone and the Septentrio PolaRx5 on the ground. However, the Bernese GNSS software does not yet fully support the estimation of kinematic positions and ZTDs for the present application. For this reason, this approach has not been pursued for the time being. A new software has to be developed that can successfully de-correlate the heights and the tropospheric delay, similar to for example the kinematic PPP software G-Nut/Geb developed at Geodetic Observatory Pecny. Although, it has been demonstrated in Václavovic et al. (2017) in a hot-air balloon experiment that even with a specialized software, there are still issues with the de-correlation of the heights and ZTDs.

\section{Summary}

In this study, we compared the tropospheric parameters calculated from the Meteodrone measurements with the values interpolated from GNSS stations surrounding the launch site. The interpolation was performed using the in-house developed least-squares software COMEDIE. Firstly, we compared the tropospheric path delays. The ZTDs determined from the Meteodrones measurements are largely in a good agreement with the values interpolated from the GNSS. We compared three methods of calculating the data: 1) using raw Meteodrone measurements vs. the interpolation model from 32 GNSS stations, 2) using processed Meteodrone measurements vs. the interpolation model from 32 GNSS stations and 3) using processed Meteodrone measurements vs. the interpolation model from 14 GNSS stations. All the comparisons 
yield similar results, although the lowest absolute bias was obtained for the comparison 2). The results have also shown that the number and height distribution of the stations used to build the interpolation model affect the interpolation. We achieved a better agreement using more stations with more diversified height distribution. The standard deviations from all methods were below $2 \mathrm{~mm}$. Furthermore, we compared the total refractivity from the best previous method. There was a small bias of $2.7 \mathrm{ppm}$ observed between the drone and GNSS models with a standard deviation of $1.7 \mathrm{ppm}$. Even though, the average statistics were very optimistic, we investigated the reasons of the instances of a worse agreement between techniques. Most of the differences are due to local changes of meteorological conditions, i.e. temperature, relative humidity and wind that are captured by the drone but not by the interpolation model.

This study was a proof of concept experiment, which showed the feasibility of calculating tropospheric path delays from the drone measurements. For the future, a more comprehensive analysis is recommended, with longer time series, flights during daytime and in the summer for more variability of water vapor. Moreover, to obtain the ZTDs directly from the low-cost dual-frequency GNSS receiver on-board the drone, a new software must be developed that can successfully de-correlate the heights and the tropospheric delay.

\section{Acknowledgments}

This work was conducted within a framework of Swiss Space Office (SSO)/Austrian Research Promotion Agency (FFG) project 'Enhanced GNSS tropospheric delay parameters for nowcasting applications' (GNSSnow) project. We thank swisstopo for providing the AGNES data, Sapos-BY and Sapos-BW for providing SAPOS data, Bundesamt fuer Eich und Vermessungswesen (BEV) for providing APOS data, TU Wien for providing EPOSA data, geotopo for providing the REFNET data and Leica (GNSS Post-Processing Package) for providing their data.

\section{References}

Alshawaf, F., Balidakis, K., Dick, G., Heise, S., Wickert, J., 2017. Estimating trends in atmospheric water vapor and temperature time series over Germany. Atmos. Meas. Tech. 10, 3117-3132.

Benjamin, S.G., Weygandt, S.S., Brown, J.M., Hu, M., Alexander, C.R., Smirnova, T.G., Olson, J.B., James, E.P., Dowell, D.C., Grell, G.A., et al., 2016. A North American hourly assimilation and model forecast cycle: The Rapid Refresh. Mon. Weather Rev. 144, 1669-1694.

Bennitt, G.V., Jupp, A., 2012. Operational assimilation of GPS zenith total delay observations into the Met Office numerical weather prediction models. Mon. Weather Rev. 140, 2706-2719.

Bevis, M., Businger, S., Herring, T.A., Rocken, C., Anthes, R.A., Ware, R.H., 1992. GPS meteorology: Remote sensing of atmospheric water vapor using the Global Positioning System. J. of Geophys. Res. 97, 15787-15801.

Bock, O., Keil, C., Richard, E., Flamant, C., Bouin, M.n., 2005. Validation of precipitable water from ECMWF model analyses with GPS and radiosonde data during the MAP SOP. Q. J. Roy. Meteorolo. Soc. 131, 3013-3036.

Boehm, J., Heinkelmann, R., Schuh, H., 2007. Short Note: A global model of pressure and temperature for geodetic applications. J. Geod. 81, 679-683. doi:10.1007/s00190-007-0135-3. 
Dach, R., Lutz, S., Walser, P., Fridez, P., 2015. Bernese GNSS Software Version 5.2. Astronomical Institute, University of Bern .

Douša, J., Dick, G., Kačmařík, M., Brožková, R., Zus, F., Brenot, H., Stoycheva, A., Möller, G., Kaplon, J., 2016. Benchmark campaign and case study episode in Central Europe for development and assessment of advanced GNSS tropospheric models and products. Atmos. Meas. Tech. 9, 2989-3008.

Duan, J., Bevis, M., Fang, P., Bock, Y., Chiswell, S., Businger, S., Rocken, C., Solheim, F., van Hove, T., Ware, R., et al., 1996. GPS meteorology: Direct estimation of the absolute value of precipitable water. J. Appl. Meteorol. 35, 830-838.

Eckert, V., Cocard, M., Geiger, A., 1992a. COMEDIE:(Collocation of Meteorological Data for Interpretation and Estimation of Tropospheric Pathdelays) Teil I: Konzepte, Teil II: Resultate. Technical Report 194, ETH Zürich. Grauer Bericht.

Eckert, V., Cocard, M., Geiger, A., 1992b. COMEDIE:(Collocation of Meteorological Data for Interpretation and Estimation of Tropospheric Pathdelays) Teil III: Software. Technical Report 195, ETH Zürich. Grauer Bericht.

Essen, L., Froome, K., 1951. The refractive indices and dielectric constants of air and its principal constituents at 24,000 mc/s. Proceedings of the Physical Society. Section B 64, 862-875.

Guerova, G., Jones, J., Douša, J., Dick, G., Haan, S.d., Pottiaux, E., Bock, O., Pacione, R., Elgered, G., Vedel, H., et al., 2016. Review of the state of the art and future prospects of the ground-based GNSS meteorology in Europe. Atmos. Meas. Tech. $9,5385-5406$.

Hadaś, T., Kapłon, J., Bosy, J., Sierny, J., Wilgan, K., 2013. Near real-time regional troposphere models for the GNSS precise point positioning technique. Meas. Sci. Technol. 24, 055003.

Haltiner, G., Martin, F., 1957. Dynamical and physical meteorology. McGraw-Hill Book Company; New York.

Hobiger, T., Ichikawa, R., Takasu, T., Koyama, Y., Kondo, T., 2008. Ray-traced troposphere slant delays for precise point positioning. Earth Planets Space 60, e1-e4.

Hurter, F., Maier, O., 2013. Tropospheric profiles of wet refractivity and humidity from the combination of remote sensing data sets and measurements on the ground. Atmos. Meas. Tech. 6, 3083-3098.

Kacmarík, M., Douša, J., Dick, G., Zus, F., Brenot, H., Möller, G., Pottiaux, E., Kapłon, J., Hordyniec, P., Václavovic, P., et al., 2017. Inter-technique validation of tropospheric slant total delays. Atmos. Meas. Tech. 10, $2183-2208$.

Karabatić, A., Weber, R., Haiden, T., 2011. Near real-time estimation of tropospheric water vapour content from ground based GNSS data and its potential contribution to weather now-casting in Austria. Adv. Space Res. 47, 1691 - 1703.

Klos, A., Hunegnaw, A., Teferle, F.N., Abraha, K.E., Ahmed, F., Bogusz, J., 2018. Statistical significance of trends in Zenith Wet Delay from re-processed GPS solutions. GPS Solut. 22, 51.

Van den Kroonenberg, A., Martin, T., Buschmann, M., Bange, J., Vörsmann, P., 2008. Measuring the wind vector using the autonomous mini aerial vehicle M2AV. J. Atmos. Ocean. Technol. 25, 1969-1982.

Leandro, R., Santos, M., Langley, R.B., 2006. UNB neutral atmosphere models: development and performance, in: Proceedings of ION NTM, pp. 564-573.

Li, X., Dick, G., Ge, M., Heise, S., Wickert, J., Bender, M., 2014. Real-time GPS sensing of atmospheric water vapor: Precise point positioning with orbit, clock, and phase delay corrections. Geophys. Res. Lett. 41, 3615-3621.

Lindskog, M., Ridal, M., Thorsteinsson, S., Ning, T., 2017. Data assimilation of GNSS zenith total delays from a Nordic processing centre. Atmos. Chem. Phys. 17, 13983-13998.

Löhnert, U., Maier, O., 2012. Operational profiling of temperature using ground-based microwave radiometry at Payerne: Prospects and challenges. Atmos. Meas. Tech. 5, 1121-1134.

Lu, C., Li, X., Zus, F., Heinkelmann, R., Dick, G., Ge, M., Wickert, J., Schuh, H., 2017. Improving BeiDou real-time precise point positioning with numerical weather models. J. Geod. 91, 1019-1029.

Manning, T., Zhang, K., Rohm, W., Choy, S., Hurter, F., 2012. Detecting Severe Weather using GPS Tomography: An Australian Case Study. J. of Glob. Pos. Sys. 11, 58-70. doi:10.5081/jgps.11.1.58. 
Möller, G., Weber, R., Böhm, J., 2014. Improved troposphere blind models based on numerical weather data. Navi. 61, $203-211$

Niedzielski, T., Skjøth, C., Werner, M., Spallek, W., Witek, M., Sawiński, T., Drzeniecka-Osiadacz, A., Korzystka-Muskała, M., Muskała, P., Modzel, P., et al., 2017. Are estimates of wind characteristics based on measurements with Pitot tubes and GNSS receivers mounted on consumer-grade unmanned aerial vehicles applicable in meteorological studies? Environ. Monit. Assess. 189, 431.

Ning, T., Elgered, G., Willén, U., Johansson, J.M., 2013. Evaluation of the atmospheric water vapor content in a regional climate model using ground-based GPS measurements. JGR. Atmospheres 118, 329-339.

Parracho, A.C., Bock, O., Bastin, S., 2018. Global IWV trends and variability in atmospheric reanalyses and GPS observations. Atmos. Chem. Phys. 18, 16213-16237.

Perler, D., Geiger, A., Hurter, F., 2011. 4D GPS water vapor tomography: new parameterized approaches. J. Geod. 85, $539-550$.

Poli, P., Moll, P., Rabier, F., Desroziers, G., Chapnik, B., Berre, L., Healy, S., Andersson, E., El Guelai, F.Z., 2007. Forecast impact studies of zenith total delay data from European near real-time GPS stations in Météo France 4DVAR. JGR. Atmospheres 112 .

Rohm, W., Guzikowski, J., Wilgan, K., Kryza, M., 2019. 4DVAR assimilation of GNSS zenith path delays and precipitable water into a numerical weather prediction model WRF. Atmos. Meas. Tech. 12, 345-361.

Rohm, W., Yuan, Y., Biadeglgne, B., Zhang, K., Le Marshall, J., 2014. Ground-based GNSS ZTD/IWV estimation system for numerical weather prediction in challenging weather conditions. Atmos. Res. 138, 414-426.

Rüeger, J.M., 2002. Refractive index formulae for radio waves. in: Proceedings, FIG Technical Program, XXII FIG International Congress, Washington DC, U.S.A. .

Seco, A., González, P., Ramírez, F., García, R., Prieto, E., Yagüe, C., Fernández, J., 2009. GPS Monitoring of the Tropical Storm Delta along the Canary Islands Track, November 28-29, 2005. Pure Appl. Geophys. 166, $1519-1531$.

Shoji, Y., Kunii, M., Saito, K., 2009. Assimilation of nationwide and global GPS PWV data for a heavy rain event on 28 July 2008 in Hokuriku and Kinki, Japan. SOLA 5, 45-48.

Smith, T.L., Benjamin, S.G., Gutman, S.I., Sahm, S., 2007. Short-range forecast impact from assimilation of GPS-IPW observations into the Rapid Update Cycle. Mon. Weather Rev. 135, 2914-2930.

Soden, B.J., Lanzante, J.R., 1996. An assessment of satellite and radiosonde climatologies of upper-tropospheric water vapor. J. Climate 9, 1235-1250.

Teke, K., Böhm, J., Nilsson, T., Schuh, H., Steigenberger, P., Dach, R., Heinkelmann, R., Willis, P., Haas, R., García-Espada, S., et al., 2011. Multi-technique comparison of troposphere zenith delays and gradients during CONT08. J. Geod. 85, 395-413.

Troller, M., 2004. GPS based determination of the integrated and spatially distributed water vapor in the troposphere. Geodätisch-geophysikalische Arbeiten in der Schweiz Vol.67, Swiss Geodetic Commission, ETH Zürich.

Václavovic, P., Douša, J., Eliaš, M., Kostelecký, J., 2017. Using external tropospheric corrections to improve GNSS positioning of hot-air balloon. GPS Solut. 21, 1479-1489.

Van Malderen, R., Brenot, H., Pottiaux, E., Beirle, S., Hermans, C., De Mazière, M., Wagner, T., De Backer, H., Bruyninx, C., 2014. A multi-site intercomparison of integrated water vapour observations for climate change analysis. Atmos. Meas. Tech. 7, 2487-2512.

Vedel, H., Huang, X.Y., 2004. Impact of ground based GPS data on numerical weather prediction. J. Meteorolo. Soc. Jpn 82, $459-472$

Vedel, H., Mogensen, K., Huang, X.Y., 2001. Calculation of zenith delays from meteorological data comparison of NWP model, radiosonde and GPS delays. Phys. Chem. Earth 26, 497-502. 
Vey, S., Dietrich, R., Fritsche, M., Rülke, A., Steigenberger, P., Rothacher, M., 2009. On the homogeneity and interpretation of precipitable water time series derived from global GPS observations. JGR. Atmospheres 114.

Wang, J., Liu, Z., 2019. Improving gnss ppp accuracy through wvr pwv augmentation. Journal of Geodesy 93, 1685-1705.

Wang, J., Zhang, L., 2008. Systematic errors in global radiosonde precipitable water data from comparisons with ground-based GPS measurements. J. Climate 21, 2218-2238.

Wielgosz, P., Paziewski, J., Krankowski, A., Kroszczyński, K., Figurski, M., 2012. Results of the application of tropospheric corrections from different troposphere models for precise GPS rapid static positioning. Acta Geophys. 60, 1236-1257.

Wilgan, K., Geiger, A., 2019. High-resolution models of tropospheric delays and refractivity based on GNSS and numerical weather prediction data for alpine regions in Switzerland. J. Geod. 93, 819-835.

Wilgan, K., Hadas, T., Hordyniec, P., Bosy, J., 2017b. Real-time precise point positioning augmented with high-resolution numerical weather prediction model. GPS Solut. 21, 1341-1353.

Wilgan, K., Hurter, F., Geiger, A., Rohm, W., Bosy, J., 2017a. Tropospheric refractivity and zenith path delays from leastsquares collocation of meteorological and GNSS data. J. Geod. 91, 117-134.

Zus, F., Wickert, J., Bauer, H.S., Schwitalla, T., Wulfmeyer, V., 2011. Experiments of GPS slant path data assimilation with an advanced MM5 4DVAR system. Meteorologische Zeitschrift 20, 173-184. 